УДК 796.093:796.344

DOI https://doi.org/10.26661/2663-5925-2021-3-07

\title{
ПОКАЗНИКИ ЗМАГАЛЬНОЇ ДІЯЛЬНОСТІ БАДМІНТОНІСТІВ НА ЕТАПІ ПОПЕРЕДНЬОЇ БАЗОВОЇ ПІДГОТОВКИ
}

\author{
Ю Лювей \\ аспірант \\ Львівський державний університет фізичної культури імені Івана Боберського \\ вул. Костюшко, 11, Львів, Украӥна \\ orcid.org/0000-0002-1674-2151 \\ ylw19890723@gmail.com
}

Каратник I. B.

кандидат наук з фізичного виховання і спорту,

дочент кафедри спортивних та рекреаційних ігор

Львівський державний університет фізичної культури імені Івана Боберського

вул. Костюшко, 11, Львів, Україна

orcid.org/0000-0001-5378-2956

karatnyk_i_v_badm@ukr.net

Пітин М. П.

доктор наук з фізичного виховання і спорту, професор,

професор кафедри теорії спорту та фізичної культури

Львівський державний університет фізичної культури імені Івана Боберського

вул. Костюшко, 11, Львів, Украӥна

orcid.org/0000-0002-3537-4745

pityn7@gmail.com

\section{Ключові слова:}

переміщення, тривалість, структура, змагальна

діяльність, бадмінтоністи.
Методологічне обгрунтування системи підготовки спортсменів визначає первинність структури та змісту змагальної діяльності у визначенні пріоритетів побудови багаторічного вдосконалення. Мета - встановити показники змагальної діяльності кваліфікованих українських бадмінтоністів на етапі попередньої базової підготовки (10-12 років). Методи - педагогічне спостереження за змагальною діяльністю бадмінтоністів на етапі попередньої базової підготовки. Отримано дані з одиночних ігор за участі 59-ти спортсменів віком 10-12 p. У педагогічному спостереженні вивчалися показники тривалості окремих компонентів гри (ігровий час першого, другого та третього гейму, загальний ігровий час та частка ігрового часу в загальній тривалості матчу), результативно-значущі техніко-тактичні дії (високо-далека подача, коротка подача, удар «високо-далекий», «свіча», «смеш», «укорот», удар «плоский», «добивання», «підставка», загальна кількість техніко-тактичних дій) та базові переміщення (короткі та довгі переміщення, переміщення стрибком). Спортсмени, які використовують згідно з регламентом змагань усі гейми, надають перевагу дещо простішим з точки зору техніки виконання та більш тривалим з огляду на тактичну схему гри. Це підтверджено більшими частками високо-далеких ударів та подач. Після їх застосування, керуючись логікою вибраного варіанту тактики, вбачають продовження змагального епізоду в укоротах, «смешах». Кваліфіковані українські бадмінтоністи в умовах змагальної діяльності мають значно більші частки коротких переміщень, що становить у середньому 74,31\% 
для матчів із двох геймів та 64,59\% для матчів із трьох геймів (за статистично вірогідної відмінності між ними $\mathrm{p} \leq 0,01)$. Українські бадмінтоністи на етапі попередньої базової підготовки (10-12 років) досягають більш швидкого результату в умовах змагальної діяльності за частішого використання дещо складніших елементів 3 огляду на вибір техніко-тактичного варіанту ведення гри із застосуванням коротких подач та «підставок».

\title{
INDICATORS OF BADMINTON PLAYERS' COMPETITION ACTIVITY AT THE STAGE OF PREVIOUS BASE PREPARATION
}

\author{
Lyuwei Yu \\ Postgraduate Student at the Department of Sports and Recreational Games \\ Lviv State University of Physical Culture named after Ivan Boberskyj \\ Kostiushka str., 11, Lviv, Ukraine \\ orcid.org/0000-0002-1674-2151 \\ ylw19890723@gmail.com \\ Karatnyk I. V. \\ PhD (Physical Education and Sport), \\ Associate Professor at the Department of Sports and Recreational Games \\ Lviv State University of Physical Culture named after Ivan Boberskyj \\ Kostiushka str., 11, Lviv, Ukraine \\ orcid.org/0000-0001-5378-2956 \\ karatnyk_i_v_badm@ukr.net \\ Pityn M. P. \\ DSc (Physical Education and Sport), Professor, \\ Professor at the Department of Theory of Sport and Physical Culture \\ Lviv State University of Physical Culture named after Ivan Boberskyj \\ Kostiushkastr., 11, Lviv, Ukraine
orcid.org/0000-0001-5378-2956
karatnyk_i_v_badm@ukr.net
}

Key words: movement, duration, structure, competitive activity, badminton players.
The methodological substantiation of the athletes' training system determines the primacy of the structure and content of competitive activities in determining the priorities for long-term improvement formation. Purpose: to establish indicators of competitive activity of qualified Ukrainian badminton players at the stage of previous base preparation (10-12 years). Methods pedagogical observation of badminton players' competitive activity at the stage of previous base preparation. There were obtained data from single games with the participation of 59 athletes aged 10-12 years. In the pedagogical observation, the indicators of the duration of individual components of the game were studied (game time of the first, second and third games, total match time and the part of game time in the total duration of the match), significant resultative technical and tactical actions (high and long serves, short serves, stroke "high-far", "candle", "smash", "shorten", stroke "flat", "finishing", "stance", the total number of technical and tactical actions) and basic movements (short and long movements, jumping movements). Athletes who use all games according to the competition regulations prefer slightly simpler actions in terms of technique performance and longer actions given the tactical scheme of the game. This is confirmed by the large parts of high 
and long strikes and innings. After these applications, guided by the logic of the chosen variant of tactics, they see the continuation of the competitive episode in shortens, "smashes". Qualified Ukrainian badminton players in competitive conditions have a much larger parts of short movements, which averages $74.31 \%$ for matches with two games and $64.59 \%$ for matches with three games (with a statistically significant difference between them, $p \leq 0.01$ ). Ukrainian badminton players at the stage of previous base preparation (10-12 years) achieve a faster result in competitive conditions with more frequent use of somewhat more complex elements given the choice of technical and tactical options for the game with the use of short innings and "stances".

Постановка проблеми й аналіз основних досліджень. Методологічне обгрунтування системи підготовки спортсменів визначає первинність структури та змісту змагальної діяльності у визначенні пріоритетів побудови багаторічного вдосконалення $[1 ; 2 ; 3 ; 4 ; 6]$.

За останній відтинок часу відбулося ущільнення техніко-тактичних дій у змагальній діяльності та загальне підвищення інтенсивності гри в бадмінтоні $[9 ; 14]$. Це своєю чергою підвищує вимоги до різних сторін підготовленості спортсменів на різних етапах багаторічного вдосконалення, зумовлює більш ранню спеціалізацію спортсменів у виді спорту, що може мати місце, починаючи 3 етапу попередньої базової підготовки $[8 ; 10 ; 11 ; 13]$.

У науковій літературі підтверджено підвищення параметрів змагальної діяльності кваліфікованих бадмінтоністів України (15-17 років) внаслідок зміни правил гри. Гравцям доводиться досить швидко переміщуватися на майданчику, раптово змінюючи напрям, раптово виконувати зупинки в зручний для удару момент та позиції тощо $[14 ; 15]$.

Зміни правил змагань та специфічні особливості змагальної діяльності, виявлені фахівцями в бадмінтоні, переконливо демонструють необхідність пошуку нових методичних підходів до різних сторін підготовки спортсменів [10; 11; 12].

Таким чином, розв'язання актуального науково-практичного завдання, пов'язаного із протиріччям між сучасними вимогами до підготовленості бадмінтоністів та недостатнім обгрунтуванням теоретичних та методичних положень їх підготовки на етапі попередньої базової підготовки, варто розпочинати з вивчення показників змагальної діяльності.

Мета дослідження - встановити показники змагальної діяльності кваліфікованих українських бадмінтоністів на етапі попередньої базової підготовки (10-12 років).

Матеріал і методи. У процесі дослідження застосовано теоретичний аналіз і узагальнення для вивчення змісту наукової та методичної літератури щодо показників змагальної діяльності в бадмінтоні; аналіз документальних матеріалів щодо регламентації змагальної діяльності; педагогічне спостереження для отримання емпіричних даних та методи математичної статистики для опрацювання отриманих даних (середнє значення, стандартне відхилення, коефіцієнт кореляції Пірсона для параметричних даних).

Педагогічне спостереження проводилося за змагальною діяльністю бадмінтоністів на етапі попередньої базової підготовки в умовах безпосередніх змагань Міжнародного дитячого турніру 3 бадмінтону «Львівські зустрічі» пам'яті М.П. Камінського (27-29.09.2019 р.). Загалом було отримано дані з одиночних ігор за участі 59-ти спортсменів віком 10-12 років.

У педагогічному спостереженні вивчалися показники тривалості окремих компонентів гри (ігровий час першого, другого та третього гейму, загальний ігровий час та частка ігрового часу в загальній тривалості матчу), результативно-значущі техніко-тактичні дії (високо-далека подача, коротка подача, удар «високо-далекий», «свіча», «смеш», «укорот», удар «плоский», «добивання», «підставка», загальна кількість техніко-тактичних дій) та базові переміщення (короткі та довгі переміщення, переміщення стрибком).

Результати дослідження та їх обговорення. Згідно 3 фундаментальними науковими даними, структура та зміст змагальної діяльності є визначальними для формування структури і змісту тренувальної діяльності. Водночас наголосимо, що специфіка підготовленості спортсменів значною мірою визначає можливості до досягнення певних показників в умовах змагальної діяльності $[2 ; 3 ; 4 ; 7 ; 14]$.

3 огляду на основну гіпотезу нашого дослідження ми припускали, що за однакового регламенту змагальної діяльності (правил змагань) спортсмени різних країні досягають різних показників реалізації та ефективності техніко-тактичних дій. На жаль, українські спортсмени лише в поодиноких випадках можуть конкурувати на європейській арені. Тому таке дослідження дає змогу отримати об'єктивні дані для корекції навчально-тренувального процесу українських бадмінтоністів на етапі попередньої базової підготовки. 
До першої групи показників змагальної діяльності ми включили лише часові параметри тривалості окремих компонентів змагальної діяльності. Це дало нам інформацію про необхідність підтримання роботи підвищеної інтенсивності впродовж окремої гри з бадмінтону (табл. 1).

На підставі проведеного аналізу змагальної діяльності українських бадмінтоністів на етапі попередньої базової підготовки (10-12 років) встановлено об'єктивну наявність двох варіантів розвитку гри. За першого матч триває впродовж двох, а за другого - трьох геймів. Загалом було проаналізовано 59 фактів змагальної діяльності українських бадмінтоністів $10-12$ років зі співвідношенням 46/13 на користь матчів, що тривали лише два гейми.

Таке співвідношення для українських бадмінтоністів ми пов'язуємо 3 наявністю певних відмінностей за рівнем підготовленості спортсменів. Вони зумовлені різним часом початку тренувань у вибраному виді спорту, різними методичними підходами до організації навчально-тренувального процесу та різним рівнем залученості спортсменів до тренувальної та змагальної діяльності. Ймовірно, ці відмінності можуть бути подолані в ході подальшої тренувальної та змагальної діяльності.

Встановлено, що за тривалістю окремих геймів (першого та другого) наявні суттєві відмінності між іграми, що складалися відповідно 3 двох та трьох геймів. У іграх 3 двох геймів тривалість першого $з$ них на 42,95 с (34,38\%) є меншою за аналогічний відрізок в іграх із трьох геймів $(\mathrm{p} \leq 0,01)$. Схожа ситуація зафіксована $\mathrm{i}$ для тривалості другого гейму гри. У матчах із двох геймів вона значно $(p=0,04)$ менша за відповідний ігро- вий відрізок ігор із трьох геймів. Відзначимо, що в межах окремих геймів спостерігаються досить великі відмінності тривалості. I за цим показником також в іграх із двох геймів спостерігається більший розкид тривалості як першого, так і другого геймів гри, порівняно 3 іграми 3 трьох геймів.

Цікавим $\epsilon$ те, що зі збільшенням кількості геймів із двох до трьох у змагальній діяльності українських бадмінтоністів загальна тривалість «чистого» часу гри збільшується майже вдвічі (на $92,83 \%, \mathrm{p} \leq 0,01$ порівняно 3 іграми 3 двох геймів). При цьому частка ігрового часу в загальній тривалості матчу для обох варіантів розвитку залишається відносно сталою (p>0,05) та становить $28,48 \%$ та 26,85\% відповідно.

Таке співвідношення тривалості різних компонентів структури змагальної діяльності українських бадмінтоністів на етапі попередньої базової підготовки ми пов'язуємо 3 напруженістю змагальної боротьби.

За двох геймів конкуренція між спортсменами $\epsilon$ дещо меншою, що може зумовлюватися певними відмінностями в рівні підготовленості та вибором тактичного варіанту ведення гри. Варіант із трьох геймів указує, що спортсмени мають більш жорстку конкуренцію на майданчику та потребують більше часу на розіграш залікових балів. Це своєю чергою збільшує тривалість як окремих ігрових ситуацій, фрагментів гри, так $\mathrm{i}$ загалом тривалість гейму (матчу).

Нами встановлено, що за абсолютними значеннями власне третій гейм має найбільшу тривалість. Це закономірно, адже в попередніх геймах кожен зі спортсменів отримував перевагу, а отже, міг формувати певне враження про слабкі та сильні сторони суперника. Наявність третього

Тривалість окремих компонентів змагальної діяльності українських бадмінтоністів на етапі попередньої базової підготовки

\begin{tabular}{|c|c|c|c|c|c|c|c|c|}
\hline № & \multicolumn{2}{|l|}{ Показник } & \multicolumn{2}{|c|}{$\begin{array}{l}\text { Зустрічі, шо завер- } \\
\text { шилися із } 2 \text {-х геймів } \\
(\mathrm{n}=46)\end{array}$} & \multicolumn{2}{|c|}{$\begin{array}{c}\text { Зустрічі, що завер- } \\
\text { шилися із 3-x геймів } \\
(n=13)\end{array}$} & \multicolumn{2}{|c|}{$\begin{array}{c}\text { Узагальнений показ- } \\
\text { ник }(\mathbf{n}=59)\end{array}$} \\
\hline \multirow{2}{*}{1} & \multirow{2}{*}{$\begin{array}{l}\text { ігровий час першого } \\
\text { гейму, с }\end{array}$} & $X$ & $124,59 *$ & $47,55^{*}$ & $167,54 *$ & $32,69 *$ & 134,05 & 44,27 \\
\hline & & $m$ & 34,05 & 5,04 & 26,66 & 3,78 & 37,11 & 7,80 \\
\hline \multirow{2}{*}{2} & \multirow{2}{*}{$\begin{array}{l}\text { ігровий час другого } \\
\text { гейму, с }\end{array}$} & $X$ & $140,01 *$ & $52,45^{*}$ & $158,77^{*}$ & $31,11 *$ & 144,15 & 47,75 \\
\hline & & $m$ & 45,34 & 5,04 & 21,32 & 3,50 & 42,00 & 10,04 \\
\hline \multirow{2}{*}{3} & \multirow{2}{*}{$\begin{array}{l}\text { ігровий час третього } \\
\text { гейму, с }\end{array}$} & $X$ & - & - & 183,92 & 36,20 & 40,53 & 7,98 \\
\hline & & $m$ & - & - & 17,77 & 4,20 & 76,69 & 15,13 \\
\hline \multirow{2}{*}{4} & \multirow{2}{*}{$\begin{array}{l}\text { загальний ігровий } \\
\text { час, с }\end{array}$} & $X$ & $264,60^{*}$ & - & $510,23 *$ & - & 318,72 & - \\
\hline & & $m$ & 75,52 & - & 29,35 & - & 122,48 & - \\
\hline \multirow{2}{*}{5} & \multirow{2}{*}{ Частка ігрового часу (\%) } & $X$ & 28,48 & - & 26,85 & - & 28,12 & - \\
\hline & & $m$ & 4,26 & - & 1,92 & - & 3,93 & - \\
\hline
\end{tabular}

Примітка: * - наявність статистично вірогідних відмінностей між показниками для зустрічей, щзо завериилися з 2-х та з 3-х партій 
гейму вказує на більшу кількість окремих розіграшів, які й формують загальну тривалість гри. Саме цим (жорстка конкуренція в першому і другому геймі та наявність третього, вирішального гейму) ми пояснюємо майже вдвічі вищі показники загальної тривалості «чистого» часу гри в іграх із трьох геймів.

Окрім часових параметрів гри, цінність становить структура та зміст виконаних кваліфікованими бадмінтоністами результативно значущих техніко-тактичних дій у межах змагальної діяльності. Загалом, для опрацювання ми запропонували дев'ять базових техніко-тактичних дій (удари, подачі, гра на сітці, табл. 2).

На підставі отриманих результатів ми спостерігаємо достовірні відмінності за більшістю абсолютних показників виконаних техніко-тактичних дій.

Аналізування даних указало нам на досить очікувану картину щодо переважання абсолютних показників виконаних техніко-тактичних дій за умови проведення матчу 3 трьох геймів. Перевагу саме такого розвитку гри зафіксовано у високо-далекій подачі, високо-далеких та пло- ских ударах, виконанні «свічі», «смешу», укороту, добиванні й загальній кількості техніко-тактичних дій. Значення таких переваг коливалися в межах від $67,94 \%$ до $170,86 \%$ на користь матчів, що завершувалися 3 трьох геймів $(\mathrm{p} \leq 0,01)$. Лише у двох випадках (коротка подача та «підставка») за абсолютними значеннями в бадмінтоністів, що завершували змагальну діяльність із двох та із трьох геймів, не спостерігалося статистично вірогідних відмінностей.

Ще один блок показників на основі вивчення техніко-тактичних дій українських бадмінтоністів пов'язаний з відсотковими частками запропонованих нами елементів у загальній структурі виконаних упродовж гри. Ця група показників указує на певний рівень інтенсивності змагальної діяльності та пріоритети спортсменів під час побудови гри 3 двох та $з$ трьох геймів.

У цьому випадку кількість статистично вірогідних відмінностей між іграми $з$ двох та трьох геймів була суттєво меншою. Лише в кількох випадках, а саме виконання високо-далекої подачі $(40,16 \%, \quad \mathrm{p} \leq 0,01), \quad$ «смешу» $(38,13 \%, \mathrm{p}=0,02)$, перевага спостерігалася на боці бадмінтоністів,

Таблиця 2

Окремі техніко-тактичні дії в змагальній діяльності українських бадмінтоністів на етапі попередньої базової підготовки

\begin{tabular}{|c|c|c|c|c|c|c|c|c|}
\hline \multirow[t]{2}{*}{ № } & \multicolumn{2}{|l|}{ Показник } & \multicolumn{2}{|c|}{$\begin{array}{c}\text { Зустрічі, що завер- } \\
\text { шилися } 32-x \text { геймів } \\
(\mathrm{n}=46)\end{array}$} & \multicolumn{2}{|c|}{$\begin{array}{c}\text { Зустрічі, шо завер- } \\
\text { шилися } 3 \text { 3-х геймів } \\
(\mathrm{n}=13)\end{array}$} & \multicolumn{2}{|c|}{$\begin{array}{c}\text { Узагальнений по- } \\
\text { казник (n=59) }\end{array}$} \\
\hline & & & абс.зн & $\%$ & абс.зн & $\%$ & абс.зн & $\%$ \\
\hline \multirow[t]{2}{*}{1} & \multirow{2}{*}{$\begin{array}{l}\text { високо-далека подача, } \\
\text { к-сть разів }\end{array}$} & $X$ & $16,80 *$ & $13,05^{*}$ & $43,69 *$ & $18,29 *$ & 22,73 & 14,21 \\
\hline & & $m$ & 11,64 & 8,80 & 11,16 & 4,75 & 16,04 & 8,37 \\
\hline \multirow[t]{2}{*}{2} & \multirow{2}{*}{$\begin{array}{l}\text { коротка подача, } \\
\text { к-сть разів }\end{array}$} & $X$ & 10,24 & $7,99 *$ & 9,92 & $4,18^{*}$ & 10,17 & 7,15 \\
\hline & & $m$ & 8,97 & 7,16 & 8,18 & 3,58 & 8,80 & 6,73 \\
\hline \multirow[t]{2}{*}{3} & \multirow{2}{*}{$\begin{array}{l}\text { удар «високо-далекий», к-сть } \\
\text { разів }\end{array}$} & $X$ & $18,57^{*}$ & 16,10 & $36,92 *$ & 15,43 & 22,61 & 15,95 \\
\hline & & $m$ & 6,75 & 8,75 & 11,24 & 4,20 & 11,01 & 7,98 \\
\hline \multirow[t]{2}{*}{4} & \multirow{2}{*}{$\begin{array}{l}\text { «свіча», } \\
\text { к-сть разів }\end{array}$} & $X$ & $23,13 *$ & 18,14 & $38,85^{*}$ & 16,14 & 26,59 & 17,70 \\
\hline & & $m$ & 12,82 & 8,73 & 12,73 & 4,92 & 14,36 & 8,09 \\
\hline \multirow[t]{2}{*}{5} & \multirow{2}{*}{$\begin{array}{l}\text { «смеш», } \\
\text { к-сть разів }\end{array}$} & $X$ & $14,15^{*}$ & $11,38^{*}$ & $38,31^{*}$ & $15,73 *$ & 19,47 & 12,34 \\
\hline & & $m$ & 7,08 & 5,96 & 15,75 & 5,25 & 13,93 & 6,09 \\
\hline \multirow[t]{2}{*}{6} & \multirow{2}{*}{$\begin{array}{l}\text { «укорот», } \\
\text { к-сть разів }\end{array}$} & $X$ & $14,50 *$ & 11,68 & $26,69 *$ & 11,14 & 17,19 & 11,56 \\
\hline & & $m$ & 10,17 & 8,63 & 9,03 & 3,55 & 11,14 & 7,80 \\
\hline \multirow[t]{2}{*}{7} & \multirow{2}{*}{$\begin{array}{l}\text { удар «плоский», } \\
\text { к-сть разів }\end{array}$} & $X$ & $7,07^{*}$ & 5,40 & $14,69 *$ & 6,23 & 8,75 & 5,58 \\
\hline & & $m$ & 5,08 & 2,97 & 7,97 & 3,71 & 6,64 & 3,16 \\
\hline \multirow[t]{2}{*}{8} & \multirow{2}{*}{$\begin{array}{l}\text { «добивання», } \\
\text { к-сть разів }\end{array}$} & $X$ & $3,28^{*}$ & 2,60 & $9,15^{*}$ & 3,75 & 4,58 & 2,85 \\
\hline & & $m$ & 2,86 & 2,42 & 4,90 & 1,97 & 4,20 & 2,38 \\
\hline \multirow[t]{2}{*}{9} & \multirow{2}{*}{$\begin{array}{l}\text { «підставка», } \\
\text { к-сть разів }\end{array}$} & $X$ & 18,48 & $13,65^{*}$ & 21,38 & $9,10^{*}$ & 19,12 & 12,65 \\
\hline & & $m$ & 12,25 & 5,89 & 12,94 & 5,93 & 12,46 & 6,19 \\
\hline \multirow[t]{2}{*}{10} & \multirow{2}{*}{$\begin{array}{l}\text { загальна кількість техніко- } \\
\text { тактичних дій, } \\
\text { к-сть разів }\end{array}$} & $X$ & $154,70^{*}$ & - & $266,46^{*}$ & - & 179,33 & - \\
\hline & & $m$ & 39,92 & - & 26,60 & - & 59,53 & - \\
\hline
\end{tabular}

Примітка: * - наявність статистично вірогідних відмінностей $(p \leq 0,05)$ між показниками для зустрічей, щзо завершилися з 2-х та з 3-х партій. 
які завершували змагальну діяльність із трьох геймів. Водночас у визначенні часток короткої подачі та «підставки» перевага спостерігалася на боці спортсменів, що завершували свою змагальну діяльність із двох геймів $(47,72 \%, \mathrm{p}=0,01$ та $33,33 \%, p=0,03)$.

Безперечно, що виконання техніко-тактичних дій повинно супроводжуватися певними переміщеннями, адже бадмінтон належить до спортивних ігор 3 високою динамічністю та зміною ігрових ситуацій. Тому в межах аналізу змагальної діяльності ми запропонували вивчити базові результативно значущі елементи переміщення. До них, згідно з рекомендаціями фахівців і структурою та змістом змагальної діяльності, належать короткі та довгі переміщення й переміщення стрибком (табл. 3).

На підставі отриманих результатів ми можемо стверджувати, що кваліфіковані українські бадмінтоністи в умовах змагальної діяльності мають значно більші частки коротких переміщень, що становить у середньому 74,31\% для матчів із двох геймів та 64,59\% для матчів із трьох геймів (за статистично вірогідної відмінності між ними $\mathrm{p} \leq 0,01)$.

Отриманий результат є очікуваним унаслідок того, що майданчик для бадмінтону має невеликі розміри та більшість техніко-тактичних дій передбачають спрямованість на «розірвання» дистанції між спортсменом та воланом. Тому для оптимального розташування спортсмени намагаються після виконання тих чи інших дій повертатися у вихідну (центральну) зону. За показниками абсолютних значень коротких переміщень передбачувана перевага за спортсменами, що змагалися впродовж трьох геймів $(89,84 \%, \mathrm{p} \leq 0,001)$. Так само більші абсолютні показники наявні для довгих переміщень та переміщень стрибком
(103,33\% та 237,56\%, p $\leq 0,01$ на користь українських бадмінтоністів, що завершили гру 3 трьох геймів).

Згідно зі структурою переміщень, серед вибраних для аналізування показників спостерігається схильність бадмінтоністів, що завершили матч із двох геймів, до коротких переміщень. Натомість спортсмени, що використали три гейми, мають достовірно вищі частки для переміщень стрибком (на 49,49\%, $\mathrm{p} \leq 0,01)$. Тобто в напруженій (конкурентній) змагальній діяльності частота використання стрибків для переміщення по корту зростає. Це вказує, що спортсменам все частіше необхідно надолужувати (випереджати) змагальну ситуацію, значно легше забезпечити використанням стрибка. Незважаючи на те, що і за коротких переміщень і за стрибків необхідно демонструвати граничну швидкість, короткі переміщення умовно можна вважати більш розміреним та планомірним варіантом переміщення 3 точки «а» в точку «б». Це ставить більш високі вимоги до розвитку вибухової сили спортсменів.

Висновки. Українські бадмінтоністи на етапі попередньої базової підготовки (10-12 років) досягають більш швидкого результату в умовах змагальної діяльності за допомогою частішого використання дещо складніших елементів та вибору відповідного техніко-тактичного варіанту ведення гри, зокрема 3 переважанням коротких подач та «підставок».

Спортсмени, які використовують згідно з регламентом змагань усі гейми, надають перевагу дещо простішим елементам із точки зору техніки виконання та більш тривалим 3 огляду на тактичну схему гри. Це підтверджено більшими частками високо-далеких ударів та подач. А вже після їх застосування, керуючись вибраною

Таблиця 3

Окремі показники переміщень у змагальній діяльності украӥнських бадмінтоністів на етапі попередньої базової підготовки

\begin{tabular}{|c|c|c|c|c|c|c|c|c|}
\hline \multirow[t]{2}{*}{ № } & \multicolumn{2}{|l|}{ Показник } & \multicolumn{2}{|c|}{$\begin{array}{l}\text { Зустрічі, що завер- } \\
\text { шилися } 32-x \text { геймів } \\
(\mathbf{n}=46)\end{array}$} & \multicolumn{2}{|c|}{$\begin{array}{l}\text { Зустрічі, що завер- } \\
\text { шилися } 3 \text { 3-х геймів } \\
(\mathrm{n}=13)\end{array}$} & \multicolumn{2}{|c|}{$\begin{array}{c}\text { Узагальнений } \\
\text { показник }(n=59)\end{array}$} \\
\hline & & & абс.3н & $\%$ & абс.3н & $\%$ & абс.3н & $\%$ \\
\hline \multirow{2}{*}{1} & \multirow{2}{*}{$\begin{array}{l}\text { короткі переміщення, } \\
\text { к-сть разів }\end{array}$} & $X$ & $84,17 *$ & $74,31 *$ & $171,15^{*}$ & $64,59 *$ & 103,34 & 72,16 \\
\hline & & $m$ & 23,51 & 9,74 & 67,31 & 6,05 & 52,24 & 9,91 \\
\hline \multirow{2}{*}{2} & \multirow{2}{*}{$\begin{array}{l}\text { довгі переміщення, } \\
\text { к-сть разів }\end{array}$} & $X$ & $13,41^{*}$ & 10,91 & $31,08^{*}$ & 13,30 & 17,31 & 11,43 \\
\hline & & $m$ & 8,82 & 4,91 & 9,42 & 5,33 & 11,56 & 5,10 \\
\hline \multirow[t]{2}{*}{3} & \multirow{2}{*}{$\begin{array}{l}\text { переміщення стрибком, } \\
\text { к-сть разів }\end{array}$} & $X$ & $17,48^{*}$ & $14,79^{*}$ & $59,00 *$ & $22,11 *$ & 26,63 & 16,40 \\
\hline & & $m$ & 10,24 & 7,22 & 25,19 & 4,67 & 22,75 & 7,39 \\
\hline
\end{tabular}

Примітка: *- наявність статистично вірогідних відмінностей $(p \leq 0,05)$ між показниками для зустрічей, щзо завериилися з 2-х та з 3-х партій. 
логікою вибраного варіанту тактики, вбачають продовження змагального епізоду в «укоротах», «смешах».

На підставі отриманих результатів ми можемо стверджувати, що кваліфіковані українські бадмінтоністи в умовах змагальної діяльності мають значно більші частки коротких переміщень, що становить у середньому 74,31\% для матчів із двох геймів та 64,59\% для матчів із трьох геймів (за статистично вірогідної відмінності між ними $\mathrm{p} \leq 0,01)$.

Перспективи подальших досліджень передбачають з’ясування відмінностей структури та змісту змагальної діяльності українських та китайських бадмінтоністів 10-12 років 3 метою вдосконалення структури та змісту системи підготовки на етапі попередньої базової підготовки.

\section{ЛITEРАТУРА}

1. Валеев Ф.Г. Повышение скоростных характеристик игры в спортивном бадминтоне с учётом лабильности нервной системы : автореф. 13.00.04 ; МГАФК. Москва, 1998. 20 с.

2. Каратник І.В. Удосконалення швидкісно-силової підготовленості бадмінтоністів на етапі спеціалізованої базової підготовки : автореф.: 24.00.01 ; ЛДУФК. Львів, 2017. 20 с.

3. Келлер В.С., Платонов В.М. Теоретико-методичні основи підготовки спортсменів. Львів : УСА, 1993. $269 \mathrm{c}$.

4. Мартынова А.С. Совершенствование методики развития координационных способностей бадминтонистов на этапе начальной подготовки : автореф.: 13.00.04. Набережные Челны, 2012. $22 \mathrm{c}$.

5. Осипов В.О. Коррекция двигательных нарушений у подростков 14-15 лет с последствиями церебрального паралича в поздней резидуальной стадии средствами бадминтона : автореф. : 13.00 .04$. Малаховка, 2006. 24 с.

6. Паршин М.С. Скоростно-силовая подготовка юных бадминтонисток 12-16 лет : автореф. 13.00.04. Москва, 2006. 24 с.

7. Рыбаков Д.П. Методика обучения технике нападающего удара в бадминтоне по материалам экспериментальных исследований : автореф. 13.00.04 ; ГДОИФК им. П.Ф. Лесгафта. Ленинград, 1976. $20 \mathrm{c}$.

8. Шиян В.М. Критерії відбору бадмінтоністів на етапі попередньої базової підготовки : автореф. : 24.00.01 ; ДДІФКіС. Дніпро, 2011. 20 с.

9. Шиян О. Обгрунтування змісту уроків фізичної культури з елементами бадмінтону для дітей молодшого шкільного віку : автореф. 24.00.02 ; НУФВСУ. Київ, 2004. 20 с.

10. Notational comparison of men's singles badminton matches between Olympic Games in Beijing and London. International Journal of Performance Analysis in Spor / P. Abián et al. 2014. 14. 42-53.

11. Cabello Manrique, D., González-Badillo, J.J. Analysis of the characteristics of competitive badminton. British Journal of Sports Medicine. 2003. 37. 62-66.

12. Effect of plyometric training on the agility of students enrolled in required college badminton programme. Journal of Sports Sciences / L.J. Heang et al. 2012. 24. 1-18.

13. Karatnyk I., Hrechaniuk O., Pityn M. Structure and content of competitive activity of 15-17 years old badminton players. Journal of Physical Education and Sport. 2015. № 15 (4). 834-837. doi: 10.7752/ jpes.2015.04128

14. Physiological characteristics of elite and sub-elite badminton players, Journal of Sports Sciences / C.H. Ooi et al. 2009. 27. 1591-1599.

15. Sturgess S., Newton R.U. Design and implementation of a specific strength program for badminton. Strength Conditioning Journal. 2008. 30. 33-41.

\section{REFERENCES}

1. Valeev F.H. (1998) «Improving the speed characteristics of a game in sports badminton taking into account the lability of the nervous system»: avtoref. dys. ... kand. ped. nauk / MHAFK. M. 20 p.

2. Karatnyk I. V. (2017) «Improvement of speed and power preparedness of badminton players at the stage of specialized basic training»: [spets.] 24.00.01 «Olimpiiskyi i profesiinyi sport». Lviv. derzh. un-t fiz. kultury. Lviv. 20 p.

3. Keller V.S., Platonov V.M. (1993) «Theoretical and methodological bases of athletes training». Lviv: Ukrainska Sportyvna Asotsiatsiia. 269 p.

4. Martynova A. S. (2012) «Improving the methodology for the development of coordination abilities of badminton players at the initial training stage» : avtoreferat dys. ... kand. ped. nauk : 13.00.04; [Povolzh. hos. akad. fyz. kultury, sporta y turyzma]. Naberezhnye Chelny. 22 p. 
5. Osypov V. O. (2006) «Correction of motor disorders in adolescents aged 14-15 with the consequences of cerebral palsy in the late residual stage by means of badminton»: avtoreferat dys. ... kand. ped. nauk : 13.00.04: Malakhovka. $24 \mathrm{p}$.

6. Parshyn M. S. (2006) «Speed-strength training of young badminton women 12-16 years old»: avtoref. dys. ... kand. ped. nauk : spets. 13.00.04. «Teoryia y metodyka fyzycheskoho vospytanyia, sportyvnoi trenyrovky, ozdorovytelnoi fyzycheskoi kultury». M. 24 p.

7. Rybakov D. P. (1976) «A technique for teaching the technique of attacking badminton strikes based on experimental research»: avtoref. dys. ... kand. ped. nauk : [spets.] 13.00.04 „Teoryia y metodyka fyzycheskoho vospytanyia y sportyvnoi trenyrovky": HDOYFK ym. P. F. Leshafta. L. 20 p.

8. Shyian V. M. (2011) «Selection criteria for badminton players in the pre-basic preparation phase»: avtoref. dys. ... kand. nauk z fiz. vykhovannia i sportu : [spets.] 24.00.01 „Olimpiiskyi i profesiinyi sport” / Shyian Volodymyr Mykolaiovych ; Dniprop. derzh. in-t fiz. kultury i sportu. D. 20 p.

9. Shyian O. (2004) «Substantiation of the content of physical education lessons with elements of badminton for children of primary school age» : avtoref. dys. ... kand. nauk z fiz. vykhovannia i sportu : [spets.] 24.00 .02 «Fizychna kultura, fizychne vykhovannia riznykh hrup naselennia»; Nats. un-t fiz. vykhovannia i sportu Ukrainy. K. 20 p.

10. Abián, P., Castanedo, A., Feng, X. Q., Sampedro, J., \& Abian-Vicen, J. (2014). Notational comparison of mens singles badminton matches between Olympic Games in Beijing and London. International Journal of Performance Analysis in Sport, 14, 42-53.

11. Cabello Manrique, D., \& González-Badillo, J. J. (2003). Analysis of the characteristics of competitive badminton. British Journal of Sports Medicine, 37, 62-66.

12. Heang, L. J., Hoek, W. E., Quin, C. K., \& Yin, L. H. (2012). Effect of plyometric training on the agility of students enrolled in required college badminton programme. Journal of Sports Sciences, 24, 1-18.

13. Karatnyk, I., Hrechaniuk, O., \& Pityn, M. (2015). Structure and content of competitive activity of 15-17 years old badminton players. Journal of Physical Education and Sport, 15 (4), 834-837. doi:10.7752/ jpes.2015.04128

14. Ooi, C. H, Tan, A., Ahmad, A., Kwong, K. W., Sompong, R., Mohd Ghazali, K. A., \& Thompson, M. W. (2009). Physiological characteristics of elite and sub-elite badminton players, Journal of Sports Sciences, 27, 1591-1599.

15. Sturgess, S., \& Newton, R. U. (2008). Design and implementation of a specific strength program for badminton. Strength Conditioning Journal, 30, 33-41. 